\title{
A Economia do Turismo e a Redução da Pobreza e da Desigualdade no Brasil: o papel do Estado ${ }^{1}$
}

\section{The Economics of Tourism and the Reduction of Poverty and Inequality in Brazil: the role of the State}

Milene Takasago ${ }^{2}$

Maria de Lourdes R. Mollo ${ }^{3}$

\section{Resumo}

Este trabalho discute o potencial do setor de turismo para reduzir a pobreza e o papel da intervenção governamental na consecução desse objetivo. Descreve, inicialmente, as principais características econômicas do turismo no Brasil e o potencial de criação de renda e empregos que ele tem. Em seguida, simula e discute alguns impactos de estímulos à demanda doméstica do turismo no aumento da renda dos mais pobres, interpretando-os e discutindo as dificuldades e cuidados a serem tomados ao desenhar políticas de combate à pobreza e à desigualdade por meio de estímulos à atividade turística.

Palavras-Chave: turismo; economia do turismo; alívio à pobreza

\begin{abstract}
This paper analyses the potential of tourism to alleviate poverty and the role of government to reach this objective. First it describes the tourism economic activity in Brazil, emphasizing the possibilities of employment and income creation. Second, it simulates some impacts of chocks on domestic demand of tourism on the income of the poor people, to discuss the difficulties and caution needed when proposing policies to alleviate poverty and to reduce income inequalities by tourism development.
\end{abstract}

Keywords: tourism, tourism economics; poverty relief

\section{Introdução}

O turismo é uma atividade econômica ainda pouco conhecida no Brasil, apesar do grande interesse recente pela mesma, tanto na academia quanto nas definições de políticas públicas relacionadas ao setor. Neste último caso, destaca-se, por um lado, o interesse em aproveitar melhor economicamente o potencial brasileiro de belezas e recursos naturais e culturais. Por outro lado, é grande o apelo que a atividade tem exercido sobre os interessados em reduzir a pobreza e a desigualdade econômica, pelas pequenas exigências de qualificação da mão de

\footnotetext{
${ }^{1}$ As autoras agradecem os comentários de Alfredo Saad Filho e Joaquim Andrade, embora seja apenas delas a responsabilidade pelas idéias aqui discutidas.

${ }^{2}$ Dutoranda e pesquisadora do Centro de Excelência em Turismo da UnB. E-mail: mtakasago@unb.br

${ }^{3}$ Professora do Departamento de Economia da Universidade de Brasília e pesquisadora do Centro de Excelência em Turismo da UnB. E-mail: mlmollo@,unb.br.
} 
obra empregada nas atividades relacionadas ao turismo e o baixo coeficiente de capital utilizado, quando comparados com o conjunto das atividades econômicas brasileiras.

Este trabalho se propõe a contribuir para essa discussão. Para tanto, o ítem 1 adiante descreve as principais características econômicas do turismo no Brasil, a relação do setor com o restante da economia e o potencial de criação de renda e empregos que ele tem. Em seguida, no item 2, o artigo simula e discute alguns impactos diferenciados de estímulos à demanda doméstica do turismo, interpretando-os no item 3, de forma a tirar conclusões sobre dificuldades e cuidados a serem tomados ao desenhar políticas públicas de combate à pobreza e à desigualdade por meio de estímulos à atividade turística.

\section{O Turismo na Economia Brasileira}

As informações que analisaremos a seguir foram obtidas a partir das matrizes de insumoproduto e de contabilidade social estimadas para o setor de turismo pelo Centro de Excelência em Turismo - $\mathrm{CET}^{4}$, da Universidade de Brasília. As matrizes foram construídas a partir de dados básicos do IBGE para 2002, contendo 54 setores de produção, 12 dos quais formam o setor de turismo (Figura 1).

Entretanto, de forma a situar o setor de turismo no restante da economia, destacamos a atividade e consolidamos a matriz original de forma a contarmos, nos quadros A e B do apêndice deste artigo, com os setores agrícola, industrial e de serviços, e o setor de turismo separado deles.

A mensuração do PIB pelas suas três óticas pode ser visualizada na Matriz de Contabilidade Social dos Quadros A e B. A matriz pode ser lida, inicialmente, pela chamada matriz de insumo-produto, cujos números estão em azul, e que explicita as relações entre os vários setores da economia. Começando pelas linhas, elas significam a produção de cada setor conforme o destino dela por setor. O setor de turismo, por exemplo, contribui sobretudo para a produção do setor de serviços ( $\mathrm{R} \$ 17.671$ milhões), e bastante menos para os demais setores.

\footnotetext{
${ }^{4}$ Além dos relatórios de pesquisa do CET-UnB, foram consultadas para a elaboração do artigo, em partiular, a matriz de contabilidade social do turismo balanceada, não publicada, e o trabalho de Arbache, Teles, Cury e Silva (2004).
} 


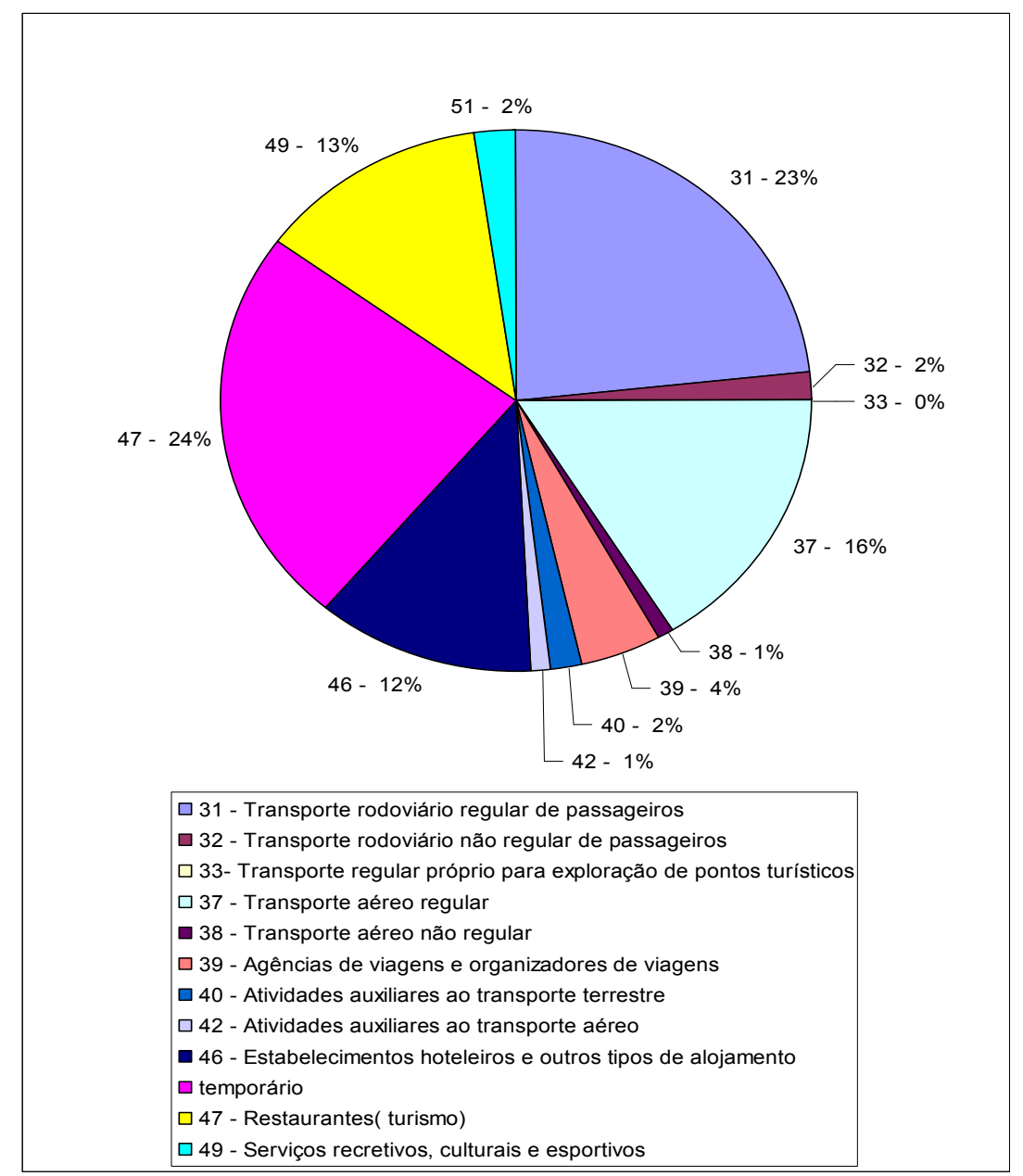

Figura 1: Participação dos Setores Formadores da Atividade Turística no PIB Fonte CET/UnB

O setor turismo é definido como o conjunto de doze subsetores ou atividades, a saber: restaurantes e outros estabelecimentos de serviços de alimentação; serviços recreativos, culturais e esportivos; transporte rodoviário regular de passageiros; transporte aéreo regular; estabelecimentos hoteleiros e outros tipos de alojamento temporário; transporte rodoviário não regular de passageiros; agências de viagens e organizadores de viagens; transporte aéreo não regular; atividades auxiliares ao transporte terrestre; atividades auxiliares ao transporte aéreo; aluguel de automóveis e outros meios de transporte; transporte regular próprio para exploração de pontos turísticos. Na Figura 1 adiante pode-se observar a participação de cada um desses subsetores na formação do turismo. Como eles atendem tanto a turistas como a residentes locais, a definição do setor de turismo é em geral superestimada. De forma a reduzir esse problema, o CET - UnB considerou apenas 58\% do subsetor restaurantes e outros 
estabelecimentos de alimentação, a exemplo do que é feito em outros países como a Espanha. Para melhorar essa estimativa, porém, para outros subsetores, é preciso pesquisas de campo mais amplas e apuradas, não disponíveis até o momento no Brasil ${ }^{5}$.

Ao observarmos a matriz de insumo-produto (números em azul no Quadro A do apêndice), podemos ver a relação entre o setor de turismo e os demais setores da economia, seja como fornecedor de insumos seja como produtor de bens intermediários ou de bens finais. A leitura da linha do setor de turismo nos diz quanto o setor fornece de insumo para os demais, assim como quanto produz de produtos finais. Assim, o turismo, por meio do setor transporte rodoviário de passageiros, por exemplo, fornece insumos para os demais setores, quando as pessoas que neles trabalham usam esses meios de transporte para trabalhar. Serviços de hospedagem, por outro lado, servem a pessoas trabalhando em setores agrícola, industrial e de serviços.

Ao observarmos, porém, a coluna do turismo, ela nos diz o que esse setor gasta consumindo dos demais, para produzir seu produto final. Assim, na coluna de turismo, temos $\mathrm{R} \$ 1.780$ milhões consumidos pelo turismo de produtos agrícolas, por exemplo, nos restaurantes que servem aos turistas ao produzir atividades turísticas. Além disso, a atividade consome $\mathrm{R} \$ 26.574$ milhões de produtos industriais para a produção turística, $\mathrm{R} \$ 11.432$ milhões de serviços e R\$ 2.859 milhões do próprio setor turístico. Um exemplo desse último caso é quando os trabalhadores do setor turístico, por exemplo, guias turísticos, se utilizam de transporte ou hospedagem na sua atividade profissional. Todos esses números correspondem a compras que o setor de turismo faz de insumos e meios de produção para produzir o total de produção turística de $\mathrm{R} \$ 82.163$ milhões que correspondem ao valor bruto da produção do turismo no Brasil em 2002. Se desse total, deduzirmos a produção intermediária do setor turístico, ou seja, os insumos que foram produzidos e já computados em outros setores (R \$42.644 milhões), temos o valor adicionado especificamente pelo setor turístico à produção econômica brasileira, que é de $\mathrm{R} \$ 39.518$ milhões. Esse é o chamado PIB do turismo no Brasil, que representa $2,8 \%$ do PIB brasileiro ${ }^{6}$.

\footnotetext{
${ }^{5}$ Esse tipo de problema deve ser melhor resolvido quando o IBGE desenvolver a chamada conta satélite do turismo do Brasil, que se encontra em elaboração. A conta satélite é uma conta de um setor específico, como turismo, ou educação ou saúde, que se pretende analisar com mais detalhes, conta essa compatível com as contas nacionais de um país.

${ }^{6}$ Estimativas anteriores davam conta de um PIB do turismo de cerca de 5\% do PIB brasileiro. Esse número, porém, levava em conta integralmente as doze atividades formadoras do setor turístico. Esse valor foi alterado a partir de balanceamento da matriz de contabilidade social e de cômputo apenas parcial das atividades de restaurantes e outros estabelecimentos de alimentação.
} 
O valor adicionado é, então, a forma de medir o PIB pelo lado do produto. Esse valor adicionado, a nível de país, sabemos, precisa ser igual à soma dos rendimentos dos fatores de produção, ou seja, à soma dos rendimentos dos trabalhadores e dos proprietários do capital, e à demanda final (Consumo + Investimento + Variação de Estoques + Gastos do Governo + (Exportação-Importação). Se observarmos a demanda final no Quadro B, onde os números se encontram em vermelho, ela tem exatamente o mesmo valor adicionado para a economia brasileira como um todo, de $\mathrm{R} \$ 1.412 .004$ milhões, que aparece no Quadro A, onde os números estão em azul. Este é o PIB brasileiro em 2002, e ele é o mesmo quando medido pela ótica do produto, em azul, ou pela ótica da renda, quando os números estão em verde, no Quadro A, e igual também quando o PIB é medido pela já mencionada ótica da despesa ou da demanda, em vermelho (Quadros A e B).

Entre os vários setores da economia, porém, essa igualdade entre a produção e os rendimentos gerados, de um lado, e a demanda final do setor, de outro, não precisa ser observada, porque alguns setores têm uma produção mais destinada à demanda final do que intermediária, enquanto outros fornecem mais insumos do que bens finais para a produção total do país. Assim, observe-se que a produção de valor agregado, na agricultura, de $\mathrm{R} \$ 108.258$ milhões (Quadro A, coluna 2 e linha 6), é maior do que a demanda final do setor agrícola, de R\$71.371 milhões (Quadro B, coluna 6 e linha 1), o mesmo ocorrendo com o setor serviços, onde o valor agregado é igual a R \$709.612 milhões, contra uma demanda final de R \$701.331 milhões. Esses são setores que fornecem muito insumo para os demais.

O setor industrial e o setor de turismo, porém, têm demanda final maior do que o valor agregado, indicando que sua produção é, sobretudo, de bens finais, e usa para produzi-los, muitos bens intermediários de outros setores, agregando menos valor novo. O setor industrial produz um valor agregado de $\mathrm{R} \$ 554.616$ milhões, contra uma demanda final de $\mathrm{R} \$ 586.764$ milhões, enquanto o setor turismo mostra-se uma atividade ainda mais voltada para o atendimento da demanda final, com uma demanda final de R\$52.539 milhões, contra uma produção de valor agregado de $\mathrm{R} \$ 39.518$ milhões. Ou seja, a contribuição do setor de turismo para o PIB brasileiro é menor do que a contribuição do mesmo para a demanda final. A participação do turismo no PIB brasileiro, já vimos, é de 2,8\%, enquanto a da demanda final é de $3,7 \%$ e a participação da produção turística no valor bruto da produção do país é de 3,2\%.

O Quadro 1 mostra a relação do setor de turismo com o conjunto da economia brasileira segundo vários aspectos. Quando se observa o tipo de remuneração paga no setor fica clara a importância relativa do trabalhador autônomo ou por conta própria no turismo, que 
corresponde a $11,35 \%$ do rendimento de trabalhadores autônomos no Brasil, contra uma participação do turismo no PIB brasileiro de apenas 2,8\%. Fica também clara a baixa participação do capital, $0,49 \%$ apenas do total do capital remunerado no país e o peso significativo do trabalhador semi-qualificado, não qualificado e qualificado, nessa ordem. Isso é uma indicação do potencial que existe no setor de turismo para geração de emprego e redução da pobreza, uma vez que a atividade pode ser tocada por pequenos empresários e trabalhadores por conta própria e a atividade não exige grandes qualificações.

Quadro 1: O setor turismo e o Brasil - R\$mil

\begin{tabular}{|c|c|c|c|}
\hline & Brasil & Turismo & $(\%)$ \\
\hline Valor Bruto da Produção & $2.543 .275 .449,92$ & $82.163 .141,50$ & $3,23 \%$ \\
\hline PIB - Valor Adicionado & $1.412 .004 .373,54$ & $39.518 .544,36$ & $2,80 \%$ \\
\hline Demanda Final & $1.412 .004 .373,54$ & $52.538 .634,88$ & $3,72 \%$ \\
\hline \multicolumn{4}{|l|}{ Remunerações } \\
\hline Trabalho não-qualificado & $73.921 .773,37$ & $3.539 .192,16$ & $4,79 \%$ \\
\hline Trabalho semi qualificado & $35.840 .432,51$ & $2.146 .461,14$ & $5,99 \%$ \\
\hline Trabalho qualificado & $194.544 .169,02$ & $7.670 .775,36$ & $3,94 \%$ \\
\hline Trabalhador por conta-própria & $61.617 .621,00$ & $6.993 .614,93$ & $11,35 \%$ \\
\hline Empregador & $47.369 .555,09$ & $1.969 .680,29$ & $4,16 \%$ \\
\hline Capital & $564.322 .855,00$ & $2.748 .302,56$ & $0,49 \%$ \\
\hline \multicolumn{4}{|l|}{ Distribuição da remuneração } \\
\hline f1: Miseráveis & $51.956 .861,72$ & $3.573 .097,50$ & $6,88 \%$ \\
\hline f2 :Renda Baixa & $143.049 .205,41$ & $8.695 .476,57$ & $6,08 \%$ \\
\hline f3 :Renda Média & $103.647 .166,26$ & $5.316 .134,27$ & $5,13 \%$ \\
\hline f4 :Renda Alta & $183.797 .060,69$ & $7.483 .318,10$ & $4,07 \%$ \\
\hline Consumo & $724.866 .357,45$ & $45.876 .970,58$ & $6,33 \%$ \\
\hline f1: Miseráveis & $61.201 .651,92$ & $2.524 .878,58$ & $4,13 \%$ \\
\hline f2: Renda Baixa & $154.783 .704,47$ & 4.222.218,08 & $2,73 \%$ \\
\hline f3: Renda Média & $154.857 .508,38$ & $6.504 .083,04$ & $4,20 \%$ \\
\hline f4: Renda Alta & $354.023 .492,68$ & $32.625 .790,88$ & $9,22 \%$ \\
\hline Investimento & $237.059 .095,61$ & $405.380,37$ & $0,17 \%$ \\
\hline Impostos indiretos & $160.523 .767,94$ & $6.749 .463,70$ & $4,20 \%$ \\
\hline Recebimento de divisas & $201.309 .528,48$ & $6.256 .283,93$ & $3,11 \%$ \\
\hline
\end{tabular}

Esse tipo de raciocínio é apenas em parte confirmado quando se analisa a participação de cada um desses rendimentos no total do valor agregado pelo setor de turismo. Isso é feito no Quadro 2.

Nele, o trabalhador por conta própria continua com a participação principal no conjunto dos trabalhadores, mas a renda dos trabalhadores qualificados é maior do que a dos não qualificados e dos semi-qualificados nessa ordem, obedecendo à mesma ordem de importância que têm no Brasil como um todo as diferentes qualificações no mercado de 
trabalho. Isso porque, apesar da elevada participação dos trabalhadores menos qualificados no turismo, relativamente ao que ocorre na economia brasileira como um todo, vista no Quadro 1, os salários dos trabalhadores qualificados são elevados, o que aumenta sua participação no valor adicionado do setor.

Ainda no quadro 2, observa-se que o peso do capital é pequeno relativamente ao que se paga aos trabalhadores, mesmo quando se considera como capital não apenas o capital propriamente dito, mas também o rendimento de empregadores e empresas ${ }^{7}$. O capital, nesse sentido mais amplo, fica com uma participação de 12,2\%, contra uma participação dos trabalhadores de 33,05\% e os trabalhadores por conta própria com 17,7\%. Essa é uma proporção de capital pequena quando comparada com a sua participação na economia brasileira como um todo que, em 2002 , era de $43,63 \%$.

Quadro 2: Remunerações dos fatores de produção como participação do valor adicionado pelo setor de turismo

\begin{tabular}{|c|c|c|}
\hline & $\begin{array}{c}\text { Participação no Valor } \\
\text { Adicionado OU NO PIB do } \\
\text { TURISMO - \% }\end{array}$ & $\begin{array}{c}\text { Participação no Valor } \\
\text { Adicionado ou no PIB } \\
\text { brasileiro - \% }\end{array}$ \\
\hline Trab. Não Qualificado & $8,96 \%$ & $5,24 \%$ \\
\hline Trab. Semi Qualificado & $5,43 \%$ & $2,54 \%$ \\
\hline Trabalho Qualificado & $19,41 \%$ & $13,78 \%$ \\
\hline Empregador & $4,98 \%$ & $3,35 \%$ \\
\hline Conta Própria & $17,70 \%$ & $4,36 \%$ \\
\hline Excedente Op. (Lucro) & $6,95 \%$ & $39,97 \%$ \\
\hline Empresas & $0,26 \%$ & $0,31 \%$ \\
\hline Impostos & $17,08 \%$ & $11,37 \%$ \\
\hline Seguridade Social & 8,46 & 10,51 \\
\hline
\end{tabular}

Fonte: NET/CET- UnB

A proporção de rendimentos de autônomos na economia brasileira como um todo, por sua vez, é bastante menor, ficando, em 2002, em 4,36\%. Embora essas observações descritivas indiquem o potencial criador de renda e redutor de desigualdades do setor de turismo, é preciso mais informações para, de fato, julgar esse potencial do setor, destacando aspectos positivos e negativos e sugerindo políticas adequadas. É o que trataremos no próximo item.

\footnotetext{
${ }^{7}$ As empresas aqui se referem a empresas financeiras e não financeiras, empresas estatais e grupos de instituições financeiras, de seguros e previdência privada.
} 


\section{O Turismo e o Combate à Pobreza no Brasil}

Conforme visto nos quadros anteriores, os baixos requisitos de capital e qualificação do trabalho e a grande participação de trabalhadores por conta própria no setor de turismo são geralmente usados para destacar o potencial de geração de emprego e renda do mesmo e, assim, o papel que o turismo pode ter na redução da pobreza no Brasil. Isso vem sendo analisado em alguns trabalhos recentes e de certa forma confirmado. É o caso do trabalho de Néri (2005), que procura estimar se houve melhorias em termos de abertura de portas para alívio à pobreza em Porto Seguro, município que foi objeto de programa de apoio turístico. As chances de uma família de Porto Seguro situar-se abaixo da linha de miséria (1/4 de salário mínimo per capita) reduziram-se em 85\% entre 1991 e 2000 . As chances de encontrar pobres em Porto Seguro são menores do que nos municípios de controle, exceto Fernando de Noronha; crescem as receitas tributárias relativamente aos demais; assim como as transferências recebidas; cresce a infra-estrutura turística. No que se refere a emprego e renda, o estudo observa que as chances de ocupação não controladas entre 1991 e 2000 crescem mais para Porto Seguro que nos demais municípios de controle, o mesmo ocorrendo com as chances de contribuição para a previdência social no período. A renda dos nativos em Porto Seguro aumenta mais do que a dos não nativos, e a renda de todos aumenta mais no período do que nos demais municípios de controle, com exceção de Maragogi. Alguns resultados negativos foram também encontrados como, por exemplo, a participação no PIB brasileiro de Porto Seguro, que cai relativamente aos demais municípios de controle. De qualquer forma, conforme mencionado, são vários os resultados positivos para o alívio à pobreza.

Outro trabalho sobre o assunto é o de Blake, Arbache, Teles e Sinclair (2004), que simulam um aumento de $10 \%$ na demanda internacional por turismo no Brasil e encontram um impacto positivo importante na redução da pobreza e da desigualdade. Como a demanda doméstica de turismo é ainda maior do que o turismo internacional no Brasil, é de se esperar que o impacto redutor de pobreza seja ainda maior. Além disso, como o consumo de turismo é muito maior nas faixas de renda mais elevadas (Quadro 1), é de se esperar um potencial particularmente redutor de desigualdades no crescimento do turismo doméstico, proporcionando uma solução sustentável de inclusão social e desconcentração de renda, caso o setor forneça o produto turístico para as classes mais abastadas. 
É exatamente isso que simulam Takasago et al.(2006), usando um modelo de equilíbrio geral computável para estimar efeitos de choques positivos sobre a demanda interna de turismo ${ }^{8}$. Isso foi feito inicialmente estimando um aumento endógeno de demanda a partir de uma redução de impostos. Essa foi simulada a partir de uma redução dos impostos incidentes sobre as doze atividades formadoras do setor de turismo, no sentido de reduzir os seus preços. Adicionamos aqui mais duas simulações: de redução de imposto de renda dos mais ricos, maiores responsáveis pela demanda de turismo, e de um aumento exógeno de demanda interna de turismo 9 .

Em cada uma dessas simulações, trabalhamos com três cenários. No cenário $\mathrm{A}$, os gastos remanescentes do governo (quando a tributação diminui) ou os gastos do governo ampliados com o aumento doméstico da demanda de turismo são destinados a bens públicos a serem consumidos pelas pessoas de todas as faixas de renda, conforme a distribuição prévia da mesma. No cenário $\mathrm{B}$, a redução ou aumento das transferências, provocados pela redução ou ampliação de impostos, se distribuem pelas faixas de renda na proporção da sua distribuição prévia. A esses dois cenários foi acrescentado neste trabalho um outro, o cenário C. Nele, todo o ônus referente à redução das transferências é repassado para a classe de renda mais elevada, e todo o ganho com aumento da arrecadação vai para a classe dos mais pobres, os miseráveis.

Os resultados dos choques acham-se sumariados nos Quadros 3, 4 e 5 e ilustrados nos Gráficos 1, 2 e 3 adiante. Observe-se, em primeiro lugar, que ao passarmos do Gráfico 1 para o 2 e depois para o 3 há redução de perdas ou melhoria de renda real em todos os cenários para as todas as classes de renda. Além disso, observe-se que tanto no Gráfico 1 quanto no Gráfico 2, quanto mais se caminha do cenário A para o $\mathrm{C}$, maiores são as reduções das perdas ou os ganhos de renda real dos mais pobres (a classe de renda mais baixa), enquanto a classe de renda mais alta perde ou ganha menos sempre. reduzindo a desigualdade e a pobreza.

\footnotetext{
${ }^{8}$ Um modelo de equilíbrio geral é a representação da economia através de um sistema fechado e interrelacionado, no qual os valores de equilíbrio das variáveis de interesse são determinados conjuntamente, a partir da igualação a priori das ofertas e das demandas, e do cálculo dos preços de equilíbrio. A partir dessa representação, choques ou mudanças em algumas variáveis da economia são simulados, e a partir de então as demais variáveis são recalculadas, por meio de compensações. O modelo de equilíbrio geral computável (CGE) permite, dessa maneira, calcular, por meio de simulações numéricas, como essas variações (choques) podem afetar a economia como um todo, supondo que os diferentes mercados retornam à posição de equilíbrio após os choques.

${ }^{9}$ Usamos aqui sugestão de Adam Blake em pesquisa conjunta em andamento, realizada pelo CET-UnB e a Universidade de Nottingham.
} 
Quadro 3: Simulação 1 - Redução de 10\% no imposto de renda das famílias com renda alta.

\begin{tabular}{|c|c|c|c|c|c|}
\hline & Cons NT ${ }^{10}$ & Cons $\mathrm{T}^{11}$ & Preço NT ${ }^{12}$ & Preço $T^{13}$ & $\begin{array}{c}\text { Renda } \\
\text { Real }\end{array}$ \\
\hline \multicolumn{6}{|l|}{ Cenário A } \\
\hline Miseráveis & $-0,931$ & $-0,991$ & 0,030 & 0,112 & $-0,148$ \\
\hline Renda baixa & $-1,096$ & $-1,188$ & $-0,003$ & 0,121 & $-0,174$ \\
\hline Renda Média & $-0,735$ & $-0,819$ & 0,027 & 0,141 & $-0,163$ \\
\hline Renda Alta & 0,825 & 0,753 & 0,086 & 0,186 & $-0,160$ \\
\hline \multicolumn{6}{|l|}{ Cenário B } \\
\hline Miseráveis & $-0,102$ & $-0,104$ & $-0,005$ & $-0,003$ & $-0,055$ \\
\hline Renda baixa & $-0,622$ & $-0,655$ & $-0,042$ & 0,002 & $-0,711$ \\
\hline Renda Média & $-0,854$ & $-0,880$ & $-0,015$ & 0,020 & $-0,986$ \\
\hline Renda Alta & 0,617 & 0,593 & 0,016 & 0,047 & $-0,631$ \\
\hline \multicolumn{6}{|l|}{ Cenário C } \\
\hline Miseráveis & 0 & 0 & 0 & 0 & 0 \\
\hline Renda baixa & 0 & 0 & 0 & 0 & 0 \\
\hline Renda Média & 0 & 0 & 0 & 0 & 0 \\
\hline Renda Alta & 0 & 0 & 0 & 0 & 0 \\
\hline
\end{tabular}

Observações:

Cenário A: redução ou aumento da renda do governo toda refletida em bens públicos consumidos por todos. Cenário B: redução ou aumento da renda do governo distribuídos via transferências entre as famílias na proporção da distribuição anterior das rendas.

Cenário C: redução da renda do governo é imputada apenas ao segmento de renda mais elevada e o ganho de arrecadação à faixa de renda mais baixa.

Na primeira simulação (do Gráfico 1), temos uma situação em que se espera que a redução da carga tributária, via aumento da renda disponível e, então, da demanda de turismo das classes mais ricas, redistribua renda para as atividades turísticas tocadas pelos mais pobres. $\mathrm{Na}$ simulação 2 temos uma situação em que se amplia a renda disponível do próprio setor de turismo mais diretamente, via redução de impostos do setor turístico. Como esse setor envolve pessoas mais pobres, quando comparadas ao conjunto da economia brasileira, a julgar pela baixa qualificação e disponibilidade de capital, há transferência mais direta de rendas para os mais pobres. Assim, quando passamos da simulação 1 para a simulação 2, estamos usando menos o mercado e mais o papel redistributivo do Estado para aumentar relativamente as rendas dos mais pobres. Na simulação 3 temos um Estado mais atuante ainda porque não se reduz a carga tributária e a arrecadação aumenta com o aumento da demanda de turismo.

Quanto aos cenários, temos que o cenário $\mathrm{A}$, onde o governo atua por meio de gastos em consumo de bens públicos, implica em maior funcionamento do mercado, porque embora esses bens estejam disponíveis igualmente para todas as faixas de renda, eles existem

\footnotetext{
${ }^{10}$ Consumo não turístico

${ }^{11}$ Consumo turístico

12 Preço não turístico

${ }^{13}$ Preço turístico
} 
sobretudo em regiões e setores mais desenvolvidos, onde o sistema de mercado funciona mais amplamente. Além disso, neste cenário a distribuição prévia da renda, determinada pelo mercado, é preservada. Nesse sentido, o cenário A depende mais do mercado do que o cenário B. Neste último, apesar de se respeitar a distribuição de renda ditada pelo mercado, o governo faz transferências diretas para cada faixa de renda, não havendo diferenciações de acesso a benefícios ligados à proximidade do mercado. A faixa de renda mais baixa ganha com essa redução de impostos porque consegue se inserir na produção turística. As classes intermediárias, todavia, não ganham com a redução de impostos do setor turístico. Por um lado consomem pouco esse seviço. Por outro, dependem de transferências do governo que caem com tal redução. Finalmente, no cenário $\mathrm{C}$, quando o governo usa seu poder discricionário para atribuir a perda de transferências provocada por redução de impostos para as classes de renda mais altas, ou o ganho maior da arrecadação para os mais pobres, os ganhos redistribuitivos são os maiores.

Quadro 4: Simulação 2 - Redução de 10\% no imposto sobre o setor de turismo.

\begin{tabular}{|c|c|c|c|c|c|}
\hline & Cons NT & Cons $\mathbf{T}$ & Preço NT & Preço T & $\begin{array}{c}\text { Renda } \\
\text { Real }\end{array}$ \\
\hline \multicolumn{6}{|l|}{ Cenário $\mathrm{A}$} \\
\hline Miseráveis & $-0,011$ & 0,522 & 0,025 & $-0,683$ & 0,009 \\
\hline Renda baixa & $-0,030$ & 0,521 & 0,019 & $-0,710$ & 0,004 \\
\hline Renda Média & 0,003 & 0,578 & 0,019 & $-0,743$ & 0,016 \\
\hline Renda Alta & 0,039 & 0,637 & 0,020 & $-0,772$ & 0,058 \\
\hline \multicolumn{6}{|l|}{ Cenário $B$} \\
\hline Miseráveis & 0,032 & 0,569 & 0,023 & $-0,689$ & 0,013 \\
\hline Renda baixa & $-0,007$ & 0,546 & 0,017 & $-0,717$ & $-0,026$ \\
\hline Renda Média & $-0,004$ & 0,574 & 0,017 & $-0,749$ & $-0,029$ \\
\hline Renda Alta & 0,029 & 0,630 & 0,016 & $-0,779$ & 0,034 \\
\hline \multicolumn{6}{|l|}{ Cenário $\mathrm{C}$} \\
\hline Miseráveis & 0,037 & 0,574 & 0,023 & $-0,688$ & 0,015 \\
\hline Renda baixa & 0,027 & 0,583 & 0,019 & $-0,717$ & 0,013 \\
\hline Renda Média & 0,041 & 0,621 & 0,018 & $-0,750$ & 0,01 \\
\hline Renda Alta & $-0,004$ & 0,598 & 0,015 & $-0,782$ & $-0,045$ \\
\hline
\end{tabular}

Observações:

Cenário A: redução ou aumento da renda do governo toda refletida em bens públicos consumidos por todos.

Cenário B: redução ou aumento da renda do governo distribuídos via transferências entre as famílias na proporção da distribuição anterior das rendas.

Cenário C: redução da renda do governo é imputada apenas ao segmento de renda mais elevada e o ganho de arrecadação à faixa de renda mais baixa.

Assim, ao caminhar dos cenários A para o $\mathrm{C}$, estamos saindo de uma situação em que se espera que o funcionamento do mercado acabe por beneficiar os envolvidos na atividade turística, a partir de choques positivos sobre a demanda doméstica, para uma situação em que 
os choques são acompanhados de transferências mais diretas de renda feitas pelo governo. Como os ganhos de renda dos mais pobres relativamente aos mais ricos crescem ao caminharmos do cenário A para o $\mathrm{C}$, temos uma situação em que quanto menos se depende do mercado, melhor se consegue reduzir a concentração de renda e a pobreza. ${ }^{14}$.

Quadro 5: Simulação 3 - Aumento exógeno de 10\% da demanda por turismo doméstico

\begin{tabular}{lccccc}
\hline & Cons NT & Cons $\mathbf{T}^{\mathbf{1 6}}$ & Preço NT $^{\mathbf{7}}$ & Preço T $^{\mathbf{8}}$ & $\begin{array}{c}\text { Renda } \\
\text { Real }\end{array}$ \\
\hline Cenário A & & & & & \\
Miseráveis & 0,340 & $-0,189$ & $-0,135$ & 0,925 & 0,106 \\
Renda baixa & 0,295 & $-0,249$ & $-0,109$ & 0,983 & 0,079 \\
Renda Média & 0,160 & $-0,460$ & $-0,136$ & 1,112 & 0,038 \\
Renda Alta & $-0,710$ & 8,558 & $-0,172$ & 1,316 & $-0,048$ \\
& & & & & \\
Cenário B & & & & & \\
Miseráveis & 0,305 & $-0,226$ & $-0,134$ & 0,930 & 0,103 \\
Renda baixa & 0,276 & $-0,269$ & $-0,107$ & 0,988 & 0,103 \\
Renda Média & 0,166 & $-0,456$ & $-0,134$ & 1,118 & 0,075 \\
Renda Alta & $-0,703$ & 8,564 & $-0,169$ & 1,322 & $-0,028$ \\
& & & & & \\
Cenário C & & & & & \\
Miseráveis & 0,596 & 0,065 & $-0,132$ & 0,931 & 0,402 \\
Renda baixa & 0,245 & $-0,301$ & $-0,109$ & 0,989 & 0,071 \\
Renda Média & 0,124 & $-0,497$ & $-0,134$ & 1,117 & 0,030 \\
Renda Alta & $-0,728$ & 8,539 & $-0,170$ & 1,319 & $-0,053$ \\
\hline
\end{tabular}

Observações:

Cenário A: redução ou aumento da renda do governo toda refletida em bens públicos consumidos por todos. Cenário B: redução ou aumento da renda do governo distribuídos via transferências entre as famílias na proporção da distribuição anterior das rendas.

Cenário C: redução da renda do governo é imputada apenas ao segmento de renda mais elevada e o ganho de arrecadação à faixa de renda mais baixa.

Esse tipo de resultado não é esperado pelos que confiam na regulação mais eficiente do mercado do que do Estado, apesar de ser um resultado de um modelo de equilíbrio geral que, por definição, simula um mercado regulador eficiente.

De fato, a percepção de mercado regulador nas concepções liberais levaria a esperar ganhos maiores de renda para a sociedade como um todo com a redução do papel discricionário do Estado e, portanto, sem tratar diferenciadamente as várias faixas de renda ao transferir os

\footnotetext{
${ }^{14}$ Um resultado desse tipo foi também encontrado em Blake, Arbache, Teles e Sinclair (2004), que ao simular um aumento da demanda externa por turismo no Brasil percebem que uma destinação das transferências governamentais para a classe de renda mais baixa dobra o benefício da expansão do turismo para esse grupo, com efeitos distributivos maiores do que outros casos examinados de distribuição de transferências conforme a distribuição prévia da renda, com redução ligeira no ganho de renda agregado do Brasil como um todo.

${ }^{15}$ Consumo não turístico

${ }^{16}$ Consumo turístico

${ }^{17}$ Preço não turístico

${ }^{18}$ Preço turístico
} 
benefícios. A idéia, nesse caso, é de que o mercado estimularia regiões e setores pouco desenvolvidos onde há maiores oportunidades de investimento e, então, maior rentabilidade, e levaria a maiores ganhos de eficiência com a ampliação da concorrência. Ocorre que, ao contrário desse tipo de expectativa, o exercício mostrou que quanto mais direta e discricionária foi a ação do Estado, melhor foram distribuídos os ganhos ou as reduções de perdas de renda, no sentido de reduzir a sua concentração que, sabemos, no Brasil é elevadíssima, beneficiando, assim, mais os mais pobres. Isso ocorre aqui especialmente quando se analisa as faixas de renda mais baixa e mais alta. Como o setor de turismo é formado principalmente de pessoas de baixa qualificação e baixa renda ele seria, nesse caso, beneficiado com esse tipo de política.

Contudo, não é possível garantir que o mero crescimento da demanda ou da produção turística cumpra esse papel redistributivo, beneficiando especialmente os mais pobres. Isso pode ser observado na simulação 1 A (Quadro 3), ou seja, na hipótese de redução de imposto de renda dos mais ricos, no cenário A. Nele, observa-se o maior aumento do consumo turístico, ou o maior impulso à demanda, mas verifica-se queda de renda real e a situação mais desfavorável aos mais pobres, negando que apenas o estímulo de mercado ao setor possa ser produtor de solução para a pobreza ${ }^{19}$. As razões para esses resultados serão analisadas no próximo item.

\section{Pobreza e Necessidade de Ação Redistributiva Direta: uma interpretação}

A interpretação desses dados requer que nos detenhamos na análise dos ajustes realizados pelo mercado. Em primeiro lugar, é preciso destacar que o mercado funciona ou ajusta-se por meio de preços que dependem de.ofertas e procuras. O resultado de tais ajustes, portanto, tende a beneficiar, em particular, aqueles que mais participam das ofertas e das procuras, para o que é necessário que se tenha recursos reais ou monetários. Ora, uma vez que a pobreza significa não apenas a ausência ou a pequena disponibilidade de recursos monetários, mas

\footnotetext{
19 Isto ocorre apesar de se estar lidando com um modelo de equilíbrio geral onde se espera um papel extremamente eficiente do mercado como regulador. São conhecidas as críticas que são feitas a esse tipo de modelo quanto ao irrealismo das hipóteses. Em particular, destacam-se entre elas: a igualdade entre oferta e demanda é suposto ou condição inicial de equilíbrio, ao invés de resultado; os preços de equilíbrio são determinados sem que nenhuma transação possa se verificar fora do equilíbrio; e observa-se a ausência da moeda para cumprir um papel de coordenação ou articulação entre setores e fases de produção. Aqui, porém, isso só fortalece a nossa percepção de que o mercado é incapaz de resolver sozinho o problema da desigualdade, porque a introdução dessas condições que implicam maior realismo só piorariam a concentração de ganhos e, então, a situação de desigualdade e pobreza, uma vez que o que se acha fora da concepção desse tipo de modelo são as imperfeições de mercado e o uso de moeda nas transações e nas articulações da economia, e é exatamente a moeda que falta aos mais pobres para que participem e obtenham ganhos no mercado
} 
também de fatores reais como educação, qualificação para o trabalho e capital e recursos naturais, é de se esperar que tais ajustes deixem à margem dos ganhos as pessoas mais pobres. Outra forma de explicar tal marginalização é observar que, em economias capitalistas como as nossas, onde se produz mercadorias, a forma de articulação entre os processos produtivos separados e das diferentes fases da produção, assim como a inserção sócio-econômica das classes trabalhadora e capitalista se dá por meio da moeda que, por isso, cumpre papel destacado na socialização dos processos de produção privados ${ }^{20} \mathrm{E}$ isso tanto mais quanto mais desenvolvida for a economia, sendo a moeda vista, por isso, como relação social importante em nossas sociedades. Ora, a pobreza, significando antes de mais nada a não disponibilidade ou a pequena disponibilidade de dinheiro, torna as pessoas impedidas ou alijadas desse processo de inserção social, ou dessa forma de socialização. Daí a dificuldade dos mecanismos de mercado os alcançarem, ou beneficiarem, ficando esse alcance, mesmo que com o objetivo explícito de inseri-los no mercado, dependente de fatores extra-mercado, como, por exemplo, o papel discricionário do Estado.

Esse tipo de conclusão é coerente com os resultados mais recentes obtidos pelas pesquisas sobre a pobreza no Brasil. Como relata de forma bem didática Arbache (2003), as conclusões mais recentes sobre o assunto destacam que as políticas sociais em geral não atenderam sempre aos mais necessitados (BARROS et al. 2000a e 2000b), razão pela qual se partiu para o esquema de políticas focalizadas, ou seja, diretamente destinadas aos mais pobres, vinculando concessão de renda e educação ${ }^{21}$.

A pesquisa da área evoluiu de uma idéia de pobreza podendo ser reduzida pelo mero crescimento econômico, para uma idéia de que sua redução está necessariamente ligada à redução da concentração de renda. De fato, Barros et al. (2000c) mostram níveis de pobreza mais sensíveis às alterações de grau de desigualdade do que de crescimento econômico, sendo necessários instrumentos de transferências mais diretas de renda para isso. Como a desigualdade de salários é explicada em grande medida pela educação, com esta última explicando, sozinha, $48 \%$ da desigualdade salarial, e cerca de $26 \%$ da desigualdade de renda

\footnotetext{
${ }^{20}$ Trata-se da concepção de moeda como relação social, que aprende a circulação de mercadorias ou o mercado como o locus privilegiado de socialização dos trabalhos privados no capitalismo, inserindo socialmente trabalhadores, via venda da força de trabalho e capitalistas, via realização de lucros (De Brunhoff 1979; Palloix, 1981).

${ }^{21}$ Esse tipo de conclusão por si só não esgota nem elimina a pertinência de algumas observações críticas dos que defendem a universalização de políticas, embora o debate universalização $\mathrm{X}$ focalização não possa ser tratado no espaço curto deste trabalho. Ou seja, como bem destaca Kersternetzky (2006), não há sempre, necessariamente, uma relação entre a concepção de mercado como melhor regulador econômico e a defesa de políticas focalizadas, nem a defesa única da universalização de políticas quando se concebe o Estado como regulador mais eficiente. Este artigo é um exemplo.
} 
(ARBACHE, 2003), a idéia dominante é de que é preciso priorizar os investimentos em educação (BARROS et al., 2000a e 2000b, e NÉRI, 2000). Daí a concepção de instrumentos como o da bolsa-família e da antiga bolsa-escola.

Outros fatores que se relacionam ou definem a pobreza são a falta de ativos como infraestrutura urbana, qualificação, bens duráveis, propriedades imobiliárias, serviços públicos em geral, ou seja, associações e instituições que lhes possibilitem lutar por melhorias sociais e econômicas em geral (NÉRI, 2000) ${ }^{22}$. Como essas condições, além das condições de salários, de renda e educação tendem a ser piores em regiões menos desenvolvidas, são também maiores as proporções de pobres nessas regiões (SAVENDOFF, 1989; BARROS e MENDONÇA, 1995).

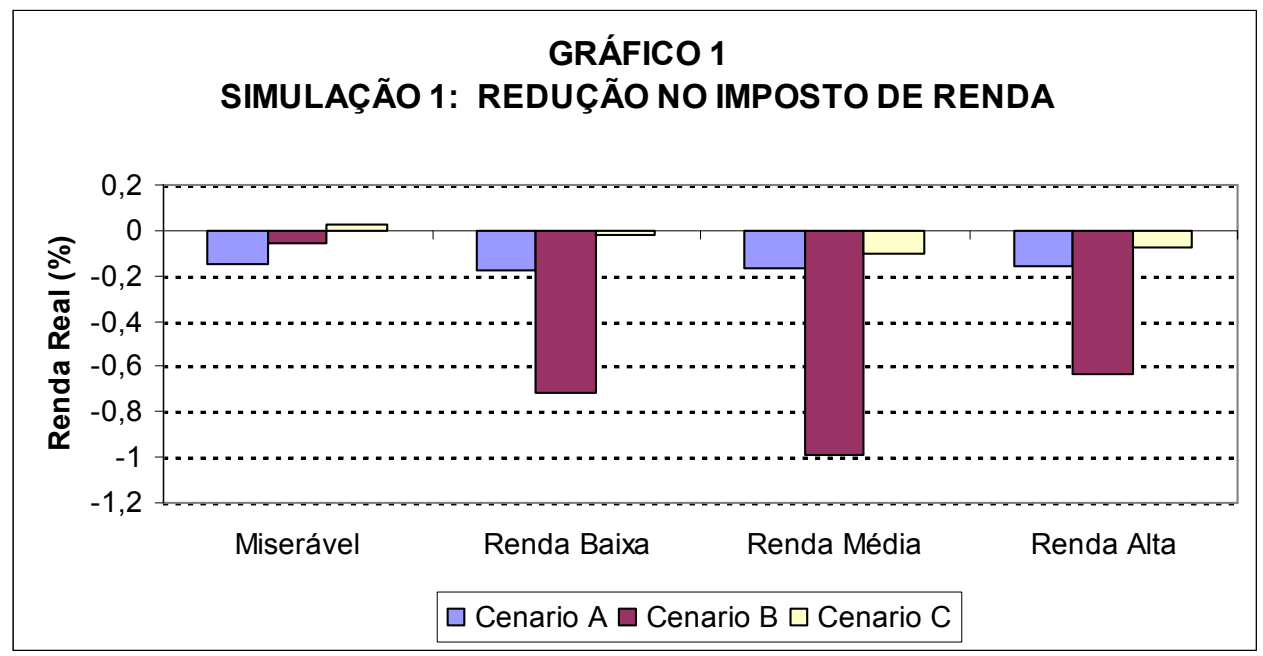

\footnotetext{
${ }^{22} \mathrm{O}$ autor usa o termo capital social para definir tais condições e recursos disponíveis. Omitimos aqui o termo por ser usado indistintamente por autores de escolas diferentes com sentidos distintos (Bourdieu,1986 e Becker, 1996 , por exemplo), o que nos parece inadequado. Além disso, e principalmente, capital implica submissão da força de trabalho requerendo sua venda como mercadoria, o que não nos parece o caso. Para uma discussão mais ampla do assunto, ver Fine, 2006.
} 

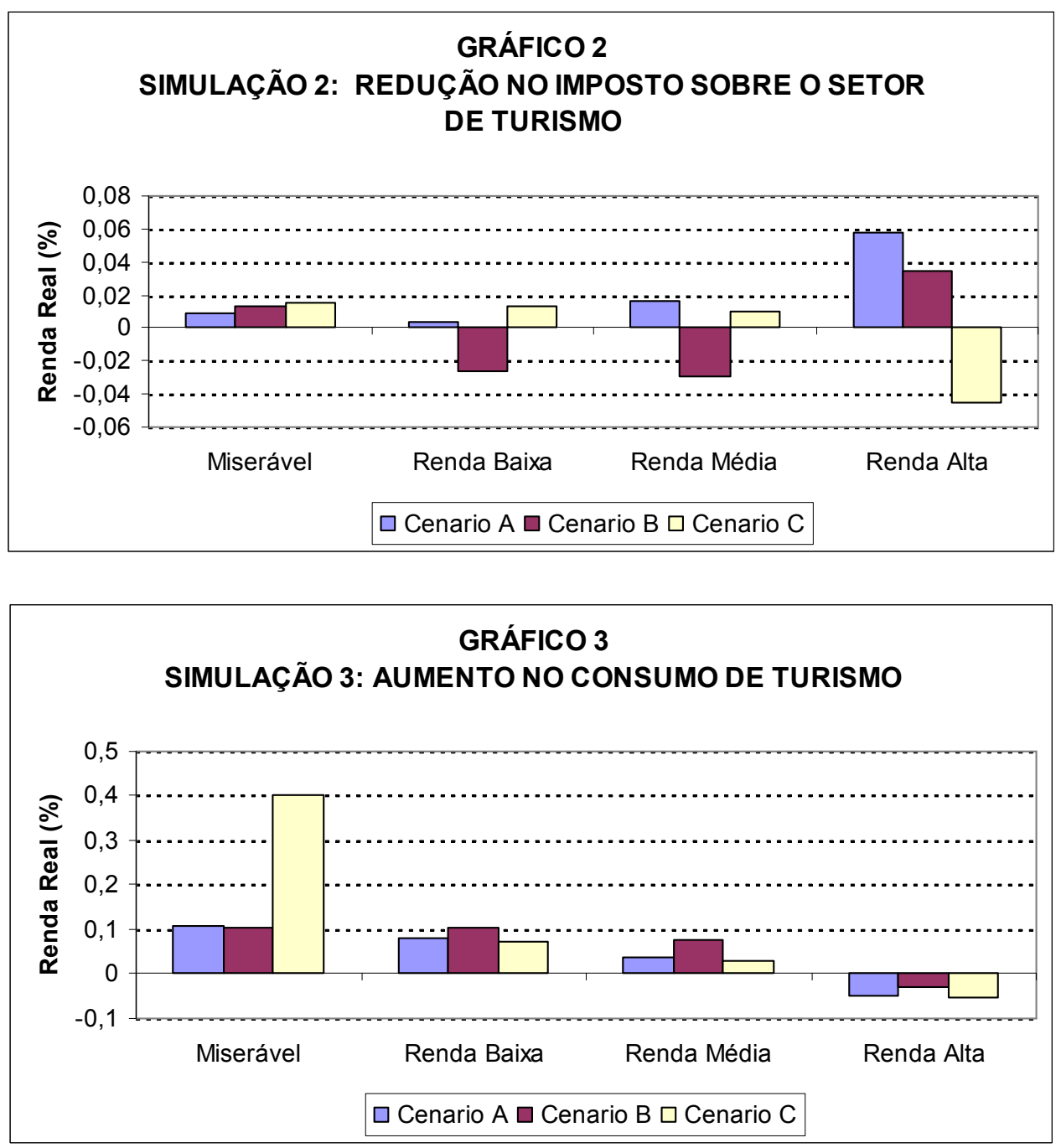

Estudos mais recentes não apenas confirmam a relação entre concentração de renda e pobreza e a necessidade de desconcentrar renda para aliviar a pobreza (MEDEIROS,2006) ${ }^{23}$, mas mostram o declínio da desigualdade no Brasil nos últimos anos (SOARES, 2006 e HOFFMAN, 2005).

Trabalho recente de Ferreira et al. (2006) mostra que o declínio da desigualdade desde 1993 relaciona-se com declínios nos retornos da educação, convergências entre a renda urbana e rural, aumento nas transferências de assistência social voltadas para os pobres e um possível declínio da desigualdade racial. A pobreza mostra relação com o crescimento econômico desde 1994 e para sua redução contribuiu sobremaneira a redução da desigualdade.

\footnotetext{
${ }^{23}$ Não se trata aqui de deixar de contemplar o papel do crescimento na redução da pobreza (Dedecca, 2005), em particular da falta de crescimento para aumentá-la, mas de enfatizar a necessidade de políticas discricionárias buscando redistribuir rendimentos.
} 
O papel dos programas de transferência de renda no Brasil para a redução desigualdade de renda é analisado por Soares, Soares, Medeiros e Osório.(2006). Em particular, encontraram que os programas Bolsa Família e Benefício de Prestação Continuada são bem focalizados, com $80 \%$ da renda do primeiro e $74 \%$ da renda do segundo indo para famílias abaixo da linha de pobreza (metade de 1 salário mínimo per capita). O trabalho mostra que esses programas (responsáveis por apenas $0,82 \%$ da renda total das famílias) foram responsáveis por $28 \%$ da redução do índice de concentração de Gini entre 1995 e 2004. As pensões e aposentadorias oficiais (públicas) no valor de um salário mínimo (responsáveis por 4,6\% da renda total declarada à PNAD) contribuíram, por sua vez, em 32\% para a redução do Gini.

Esses fatores explicativos da pobreza e o sucesso redistributivo das políticas dirigidas são suficientes para mostrar que há barreiras à participação nos mercados pelos pobres, o que, numa economia regida por ele, tende a prejudicá-los, mesmo quando se trata de estimular atividades onde eles apresentam elevada participação como trabalhadores contratados ou autônomos, como é o caso do setor de turismo, se não houver mecanismos de criação e sustentação de renda que lhes permita galgar um patamar de condições de produção suficientemente forte para resistir minimamente às flutuações e ajustes de mercado. Não por acaso os trabalhos que analisaram o impacto das políticas de liberalização dos mercados (ARBACHE, 2001 e 2002) não se verificaram nem redução de desemprego nem de desigualdade de rendas, como as teorias neo-liberais esperavam, não contribuindo, portanto, para reduzir a pobreza.

Observe-se, além disso, que ao falarmos da moeda como relação social em economias produtoras de mercadorias como a capitalista e assim destacarmos a circulação de mercadorias como espaço privilegiado de inserção social e socialização, estamos condicionando esse processo sempre à obtenção de renda, priorizando-a relativamente à educação. Isso ocorre porque embora a educação possa proporcionar melhorias de renda por meio de remunerações maiores por trabalhos mais qualificados, grande parte da educação se dá por meio de valores e ativos cujo acesso está condicionado à obtenção de rendas. Mesmo que a educação pública busque resolver esse problema e, de fato, contribua nesse sentido, o processo de educação requer ativos como computadores, televisores, meios de comunicação, acesso a ambientes culturais desenvolvidos, etc. que só estão disponíveis para os que têm rendas altas. Além disso, essas condições diferenciadas ampliam constantemente as desigualdades de renda e de oportunidades. 
Finalmente, como já mencionamos, a inserção social e a socialização nas sociedades produtoras de mercadorias como as nossas se intensifica quanto maior for a produção e a circulação das mesmas, evoluindo com o desenvolvimento do capitalismo. Daí a convivência, em regiões mais pobres e menos desenvolvidas, com formas de socialização menos relacionadas com as operações monetárias e, assim, menos sujeitas e ligadas à lógica de maximização de lucros. Isso explica, por um lado, o despreparo das regiões e das populações mais pobres para desenvolverem negócios, mesmo depois de inseridos em sistemas formais de educação e qualificação, e a dificuldade de quebrar hábitos de vida que se opõem à chamada eficiência econômica. É o caso, por exemplo, de dificuldades para que os pequenos negócios mantenham horários de atendimento padronizados e respeitem regras de atendimento que privilegiem o cliente.

Esse gênero de diferenciação nas normas de socialização explica a dificuldade de acesso à população mais pobre. Essa dificuldade de acesso explicita-se na falta de participação dos pobres nas decisões, em programas de combate à pobreza; na falta de percepção dos reais problemas por eles enfrentados em cada região por não serem ouvidos ${ }^{24}$; na dificuldade deles perceberem oportunidades potenciais de negócios a serem aproveitadas; e na dificuldade de atraí-los para negócios novos. Observa-se, ainda, a dificuldade de percepção, pelos pobres, dos requisitos mínimos necessários à prestação de serviços de qualidade no turismo ou em qualquer outra atividade.

Como descreve Medeiros (2005), os ricos no Brasil são uma pequena elite reduzida, enquanto os pobres são uma massa homogênea de famílias de baixos rendimentos. A esse respeito é importante notar que o aproveitamento da demanda de turismo da classe de renda mais alta para desenvolver uma atividade econômica realizada, sobretudo, pelos mais pobres, inserindoos produtiva e economicamente de forma sustentada, exige uma qualidade elevada na prestação do serviço, e requer sofisticação do próprio serviço, sob pena da atividade perder demanda para a o turismo externo, de outras regiões mais desenvolvidas do país ou do exterior. Trata-se, portanto, de conceber, planejar e preparar o produto ou o serviço turístico, ao invés de simplesmente oferecer serviços beneficiando-se de paisagens ou recursos naturais atrativos já disponíveis, o que requer a participação do governo. Não por acaso, é conhecido que um dos fatores importantes na atração de turistas é o grau de desenvolvimento da infraestrutura local de serviços. Assim, de novo a política pública de inserção social tem um papel

\footnotetext{
${ }^{24}$ Em trabalho que analisa várias iniciativas de combate à pobreza, Cattarinich (2001) relata, por exemplo, que faltam, em todas elas, ouvir os próprios pobres sobre a compatibilidade entre as iniciativas e suas formas de vida.
} 
direto na formação, treinamento e até no efeito demonstração, permitindo que a população empregada no setor de turismo tenha acesso e conhecimento do que é possível oferecer em termos de qualidade e variedade de serviço, colocando-se ela própria na posição do turista, via, por exemplo, o chamado turismo social.

Esse conflito entre uma forma arcaica de estruturação da economia e de socialização dos trabalhos privados e a forma mercantil desenvolvida tem sido responsável, no desenvolvimento do turismo em geral, e no Brasil em particular, por conseqüências sociais negativas importantes em algumas áreas e por dificuldades não desprezíveis para as políticas de desenvolvimento regional (MINISTÉIRO DO TURISMO, 2005). Por um lado, diversos são os casos em que a instalação de empreendimentos de grande porte do tipo resort desestrutura a economia local, e o modo de vida anterior de suas populações, sem substituí-lo por atividade econômica viável e sustentável. Assim, longe de inserir social e economicamente a população local, os grandes empreendimentos podem ampliar a exclusão social e econômica.

Por outro lado, é difícil ensinar e comprometer as populações locais com a preparação do produto turístico de qualidade adequada no sentido de prestar serviços em termos de sofisticação e conforto compatíveis com o padrão elevado de qualidade exigido pelos consumidores de alta renda.

Esse tipo de obstáculos e conseqüências reproduz processos e tendências concentradoras de riqueza e renda regionais por meio de vazamentos de renda de regiões/países menos desenvolvidos para regiões/países mais desenvolvidos, na direção inversa do que as teorias de desenvolvimento econômico liberais esperam. De fato, estas últimas esperam sempre convergência de níveis de desenvolvimento, reduzindo desigualdade por processos de crescimento promovidos pelos mercados. Os argumentos até aqui discutidos mostram, ao contrário, que pode haver divergência e aumento da desigualdade. Lugares e populações mais pobres e menos desenvolvidos têm pouco poder de expressão no mercado e ficam sujeitos a uma lógica que os pune.

Assim, a falta de renda para consumir produtos afasta os investimentos e os re-investimentos na região; a falta de qualificação impede a produção local de produtos sofisticados que segure internamente a renda dos consumidores visitantes; a qualidade inferior dos serviços turísticos prestados, pode afastar consumidores novos ou com maior potencial para gastar; a falta de conhecimento das possibilidades de produtos ou serviços a oferecer impede a preparação de um produto ou serviço compatível com o que a demanda requer. Há que se recorrer, portanto, 
a mecanismos e instituições extra-mercado para inserir econômica e socialmente a população mais pobre. São essas argumentações que justificam políticas como as relacionadas com a economia solidária, o micro-crédito e o turismo social, embora não se esgotem nelas.

\section{Conclusão}

Procuramos neste artigo discutir a questão do turismo como atividade cujo desenvolvimento pode ser utilizado buscando a redução da pobreza e da desigualdade sociais brasileiras. Mostramos indícios desse potencial, por meio da descrição da matriz de contabilidade social do Brasil para o setor turístico. Em seguida, utilizamos os resultados do trabalho de Takasago et al. (2006) e introduzimos novas simulações de aumentos da demanda e de destino das transferências do governo, para mostrar que os impactos positivos de aumentos da demanda de turismo sobre a redução da pobreza e da desigualdade não podem ficar à mercê do mero desenvolvimento do setor dentro das regras do mercado. Ao contrário, esses ganhos dependem sempre mais de um papel ativo e discricionário do Estado no setor, tendo em vista a dificuldade das classes mais pobres se integrarem aos mercados e se beneficiarem da sua lógica de funcionamento. Assim, a mera importância das classes de rendas mais baixas na atividade turística, e os pequenos requisitos de capital não garantem por si só ganhos de inclusão social pelo desenvolvimento do setor.

Ao discutir e interpretar esses resultados justificamos um papel do Estado mais ativo pela dificuldade que têm essas classes mais pobres de se inserirem na lógica mercantil, seja por falta de disponibilidade monetária, seja por uma menor articulação das comunidades onde vivem com formas de socialização monetárias comuns às sociedades capitalistas desenvolvidas. Nesse sentido, as políticas públicas destinadas à inserção dessas populações em sistemas econômicos minimamente sustentáveis dentro da lógica do mercado requerem um processo lento e complexo de adaptação, formação e estruturação, que exige um papel ativo de organizações extra-mercado, em particular do Estado, durante uma etapa prolongada de implantação de atividades novas, enquanto se introduzem novas atividades substituindo as anteriores, sob pena de se ver desestruturada uma forma de organização econômica anterior sem que se implante a nova, desorganizando a sociedade local.

\section{Referências Bibliográficas}


ARBACHE, J. S. 2001. Abertura commercial e mercado de trabalho no Brasil, M. B. Lisboa e N. A. Menezes-Filho (Orgs.), Microeconomia e Sociedade no Brasil, Rio de Janeiro: Contra Capa e EPGE/FGV

2002. Trade liberalization and labor markets in developing countries: theory and evidence, A. Levy e J. R. Faria (Eds.), Economic Growth, Inequality and Migration: National and International Perspectives, Cheltenham: Edward Elgar.

. 2003. Pobreza e Mercados no Brasil, Pobreza e Mercados no Brasil - uma análise de iniciativa de políticas públicas, CEPAL - Escritório da Cepal no Brasil/DFID, Brasília.

BARROS, R. P. e MENDONÇA, R. 1995. Os determinantes da desigualdade no Brasil, Texto para Discussão n. 377, IPEA.

BARROS, R. P. et al. 2002a. Evolução recente da pobreza e da desigualdade: marcos preliminares para a política social no Brasil, Cadernos Adenauer N. 1, Fundação Konrad Adenauer.

BARROS, R. P. et al. 2000b. A estabilidade inaceitável: desigualdade e pobreza no Brasil, R. Henriques (Org.), Desigualdade e Pobreza no Brasil, Rio de Janeiro: IPEA.

BARROS, R. P. et al. 2000c. Education and equitable development, Economia, 1(1).

BLAKE, A. , ARBACHE, J., TELES, V. E SINCLAIR, T. 2005. Tourism and Poverty in Brazil, Fórum Mundial de Turismo para a Paz e Desenvolvimento Sustentável, Rio de Janeiro, novembro. Disponível em: <www.unb.br/cet>.

CENTRO DE EXCELÊNCIA EM TURISMO (CET).2004.Matriz de Contabilidade Social do Turismo , mimeo, Núcleo de Economia do Turismo, Centro de Excelência em Turismo CET-UnB.

FERREIRA, F. H. G, ,LEITE, P. G. E LITCHFIELD, J. A. 2006. The Rise and Fall of Bazilian Inequality: 1981-2004, World Bank Policy Research Working Paper 3867, March.

MEDEIROS, M. 2005. O estudo dos ricos no Brasil, Econômica, v. 7 n. 1, junho.

NÉRI, M. 2005. Turismo Sustentáveil e Alívio à Pobreza (TS-AP): Avaliação de Impacto em Destinos Tuísticos - Arcabouço Geral e Piloto para Porto Seguro. Rio de Janeiro: IPEA.

. (2000). Políticas estruturais de combate à pobreza no Brasil, R. Henriques (Org.), Desigualdade e Pobreza no Brasil, Rio de Janeiro: IPEA.

SAVENDOFF, W. D. 1989. Regional Wage Differentials and Segmentation in Brazil's Urban Labor Market, Fortaleza: Anais do XI Encontro Brasileiro de Econometria.

SOARES, F. V. , SOARES, S., MEDEIROS, M. E OSÓRIO, R. G. 2006. Cash Transfer Programmes in Brazil: Impacts on Inequality and Poverty, UNDP: International Poverty Centre Working Paper number 21, June. DIsponível em: $<$ www.undp.org/povertycentre $>$.

SOARES, S. 2006. Distribuição de Renda no Brasil de 1976 a 2004 com Ênfase no Período entre 2001 e 2004, Brasília : IPEA, Texto para Discussão n. 1166.

TAKASAGO, M. et al. 2006. Impactos do Turismo na Economia Basileira: aplicação de modelo de equilibrio geral computável, Brasília: CET-UnB.

\section{Recebido em: 12/9/2006 ( $1^{\mathrm{a}}$ versão) $16 / 02 / 2007$ ( $2^{\mathrm{a}}$ versão) Aprovado em: 19/03/2007}




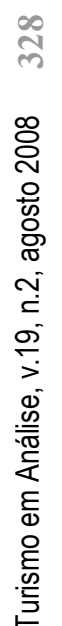

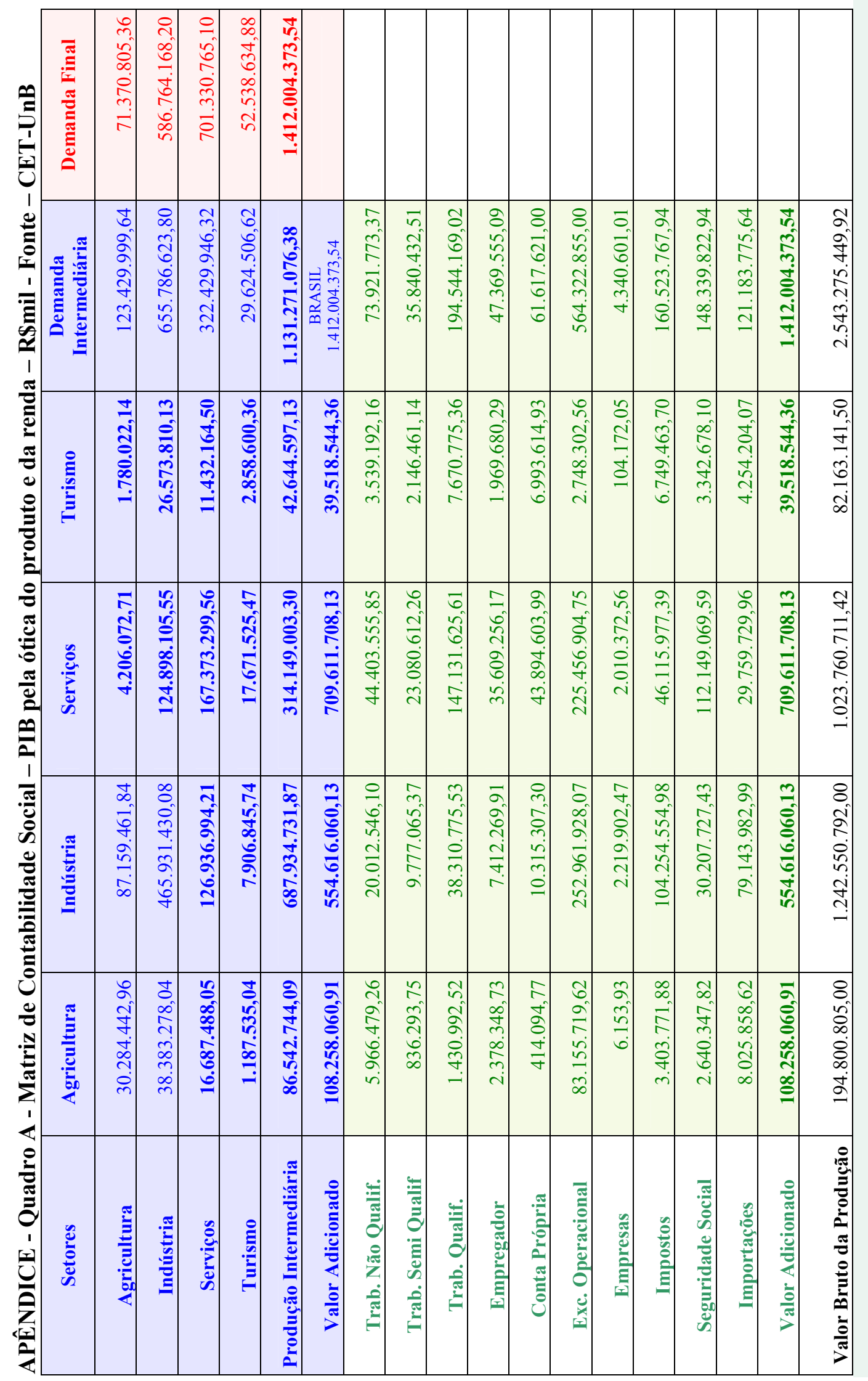


तै

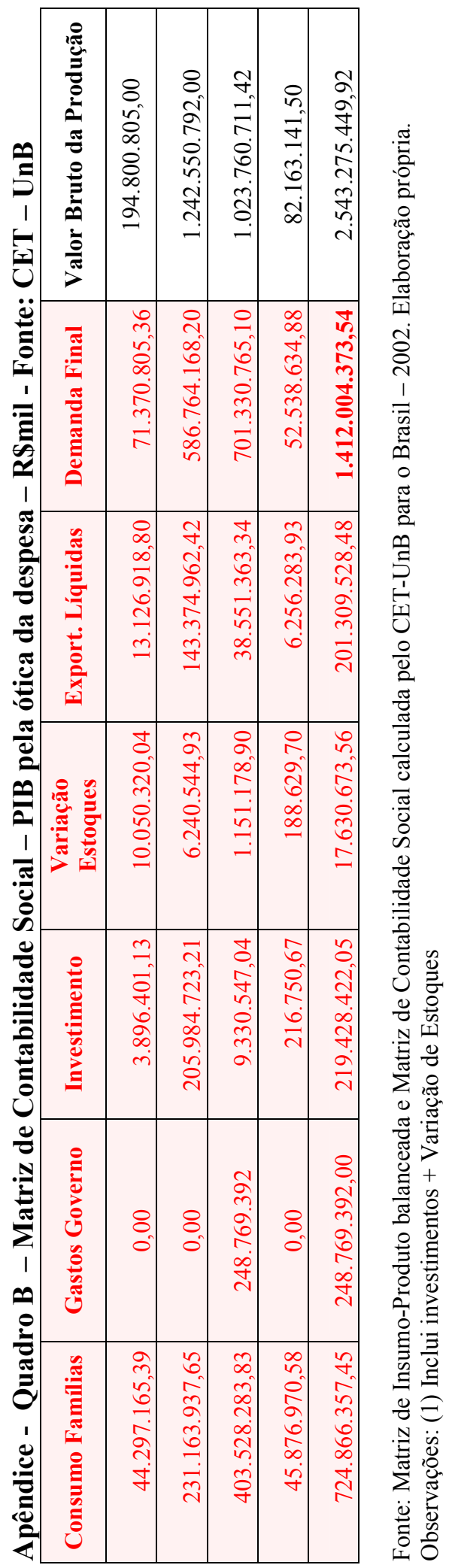

